\title{
Analysis \& Optimization of Parameters during EDM of Aluminium Metal Matrix Composite
}

\author{
D.O.I - 10.51201/Jusst12671 \\ http://doi.org/10.51201/Jusst12671 \\ Mumtaz Rizwee $^{1 *}$, Dr. P. Sudhakar Rao ${ }^{2}$ \\ ${ }^{I}$ M.E. Scholar, Department of Mechanical Engineering, National Institute of Technical Teachers Training \\ and Research (NITTTR), Chandigarh (India). \\ ${ }^{2}$ Assistant Professor, Department of Mechanical Engineering, National Institute of TechnicalTeachers' \\ Training and Research (NITTTR), Chandigarh (India).
}

\begin{abstract}
In now days Aluminium Metal Matrix Composite (AMMC) has become one of the most favorite material for automotive, aerospace, shipyard etc. industry because of their outstanding properties such as high wear and corrosive resistance, remarkable hardness and toughness, low density, light weight etc. But because of the complexity of the cutting geometry and mechanical properties of work materials the use of convectional machining process becomes limited. Such difficulties are easily sort-out by using electric discharge non convectional machining process (EDM) because in this case material removal takes place by thermal erosion process. The present research work highlight the effect of process parameter on output response during the EDM of Aluminium7075- Boron carbide-Graphite $\left(A l / B_{4} C / G r\right)$ metal matrix composite $(M M C)$. Taguchi technique is used for design of experiments. Fitness and adequacy of the experimentation has tested through the analysis of variance (ANOVA).
\end{abstract}

Keywords: EDM, AMMC, Taguchi, Process Parameter, ANOVA, Process Responses.

\section{INTRODUCTION}

Metal matrix composite materials are one of the newly developed materials and in now days it has becomes the interest of the industries because of their superior mechanical properties. But it is very difficult to machine such materials through convectional machine tool because of high tool erosion. Such a problem can be short out through the non convectional machining process. Hence non convectional machining process is most suitable to machine said materials. Among all non convectional machining process Spark erosion machining (EDM) process is mostly used to machine such materials [1,2]. George et al. [3] evaluated the optimal setting of input parameter through Taguchi technique in term of pulse current $(\mathrm{I})$, gap voltage $\left(\mathrm{V}_{\mathrm{g}}\right)$, spark on time $\left(\mathrm{T}_{\mathrm{ON}}\right)$ for getting better responses in term of electrode wear rate (EWR) and material removal rate (MRR) during EDM of carbon-carbon composite material. Pandey and Shrivastava [4] compared the conventional EDM and vibration assisted electric arc machining (VEAM) during the machining of $\mathrm{Al} / \mathrm{B}_{4} \mathrm{C}$ MMC. Result implied that VEAM enhanced the MRR $300 \%$ more as compare to conventional EDM. Khan et al. [5-7] was found out the effect of biodiesel and powder mixed di electric fluid on the machining performance of EDM.

\section{EXPERIMENTAL DETAILS}

OCARMAX EDM machine was chosen to conduct the experiment which was manufactured by OSCAR E.D.M. Company Ltd. Taichung, Taiwan (shown in Fig. 1) in Indo Danish Tool Room (IDTR), Jamshedpur, Jharkhand. AMMC metal matrix was selected as work piece materials. Three different percentage of weight fraction of boron carbide $\left(\mathrm{B}_{4} \mathrm{C}\right)$ and graphite $(\mathrm{Gr})$ were reinforced with $\mathrm{Al}-7075$ such as $3 \%$ wt. $\mathrm{B}_{4} \mathrm{C} \& 7 \%$ wt. Gr, $5 \%$ wt. $\mathrm{B}_{4} \mathrm{C} \& 5 \%$ wt. Gr, $7 \%$ wt. $\mathrm{B}_{4} \mathrm{C} \& 3 \%$ wt. Gr respectively. The MMC was developed through the stir casting process. Experiments was performed by using copper electrode having diameter $18 \mathrm{~mm}$ with negative polarity and fluid SE 180 as a di-electric fluid during the EDM of $\mathrm{Al} / \mathrm{B}_{4} \mathrm{C} / \mathrm{Gr}$ metal matrix composite materials.

Chemical composition of Al-7075 is tabulated in table 1. In this research h work four input parameter with their three levels was selected to perform the experiments (shown in table 2) and kept spark off time $150 \mu$ sec and tool workpiece gap $10 \mathrm{~mm}$ constant. Operational setup is shown in Fig. 2. 


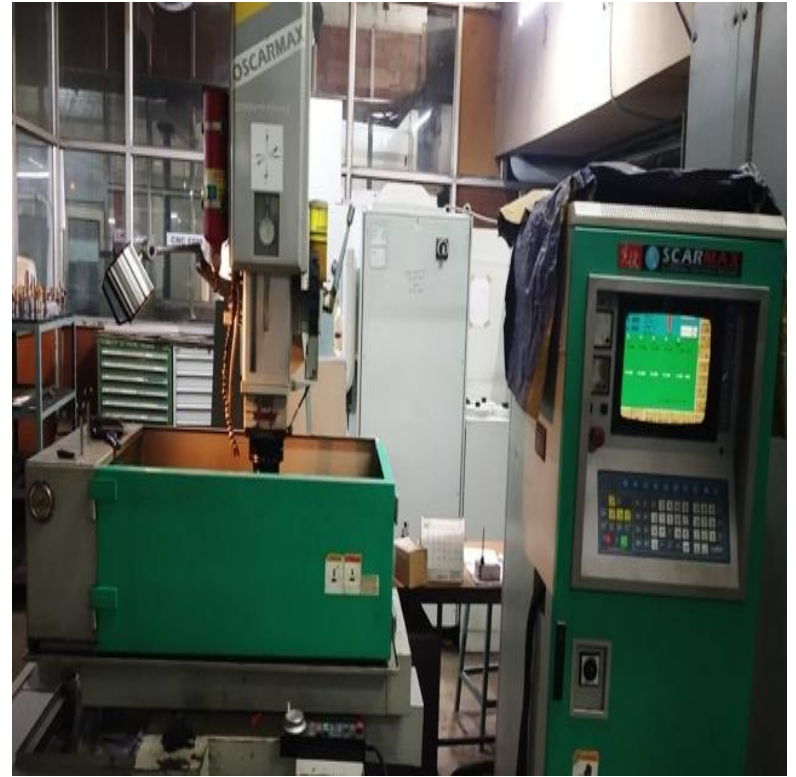

Fig. 1 Spark Erosion Machine

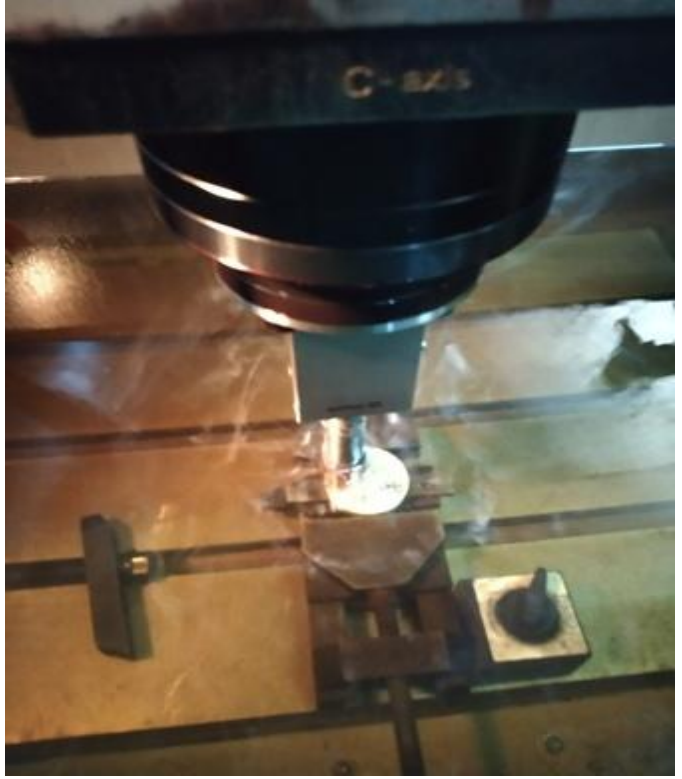

Fig. 2 Operational setup of EDM machine

Table 1. Chemical composition of Al-7075 alloy

\begin{tabular}{|c|c|}
\hline Composition & Percentage $(\%)$ \\
\hline Aluminium $(\mathrm{Al})$ & 89.60 \\
\hline Zinc $(\mathrm{Zn})$ & 5.70 \\
\hline Magnesium $(\mathrm{Mg})$ & 2.30 \\
\hline Copper $(\mathrm{Cu})$ & 1.50 \\
\hline Ferrous $(\mathrm{Fe})$ & 0.41 \\
\hline Chromium $(\mathrm{Cr})$ & 0.18 \\
\hline Silicon $(\mathrm{Si})$ & 0.13 \\
\hline Manganese $(\mathrm{Mn})$ & 0.13 \\
\hline Titanium $(\mathrm{Ti})$ & 0.05 \\
\hline
\end{tabular}

Selection of level of input variable was done through the study of literature survey [8-12]. By using Taguchi Technology total 09 experiments were designed as shown in table 3. Wear Ratio (WR) was considering as a machining responses during the research work.

Table 2. Independent variable and their levels

\begin{tabular}{|c|c|c|c|}
\hline Process parameter & Low level & Medium level & High level \\
\hline Survo voltage $(\mathrm{V})$ & 3 & 6 & 500 \\
\hline Spark on time $(\mu \mathrm{sec})$ & 300 & 400 & 6 \\
\hline Pulse current $(\mathrm{A})$ & 2 & 4 & 3 \\
\hline Sample & 1 & 2 & 5 \\
\hline
\end{tabular}




\section{MEASUREMENT OF RESPONSE VARIABLES}

Tool Wear Rate (TWR) and Material removal rate (MRR) had been founded through the weight method [13, 14]. Wear Ratio (WR) is defined as the ratio of MRR to TWR and mathematically it can be expressed as

$$
\mathrm{WR}=\frac{M R R}{T W R}
$$

The experimental finding of machining responses such as MRR, TWR and WR has been shown in table 4 .

Table 3. L9 Orthogonal Matrix

\begin{tabular}{|c|c|c|c|c|}
\hline Experiment no. & Survo voltage (V) & Spark on time ( $\boldsymbol{\mu s e c})$ & Pulse current (A) & Sample \\
\hline 01 & 3 & 300 & 2 & 1 \\
\hline 02 & 3 & 400 & 4 & 3 \\
\hline 03 & 3 & 500 & 6 & 3 \\
\hline 04 & 6 & 300 & 4 & 2 \\
\hline 05 & 6 & 400 & 6 & 2 \\
\hline 06 & 6 & 500 & 2 & 3 \\
\hline 08 & 9 & 300 & 6 & 1 \\
\hline
\end{tabular}

Table 4. Experimental determination for output responses

\begin{tabular}{|c|c|c|c|c|c|}
\hline Serial no. & $\begin{array}{c}\text { Survo } \\
\text { voltage } \\
(\mathbf{V})\end{array}$ & $\begin{array}{c}\text { Spark } \\
\text { on } \\
\text { time }\end{array}$ & $\begin{array}{c}\text { Pulse } \\
\text { current } \\
(\mathbf{A})\end{array}$ & Sample & WR \\
\hline 01 & 3 & 300 & 2 & 1 & 55.988 \\
\hline 02 & 3 & 400 & 4 & 2 & 30.510 \\
\hline 03 & 3 & 500 & 6 & 3 & 24.007 \\
\hline 04 & 6 & 300 & 4 & 3 & 41.417 \\
\hline 05 & 6 & 400 & 6 & 1 & 27.653 \\
\hline 06 & 6 & 500 & 2 & 2 & 31.042 \\
\hline 07 & 9 & 300 & 6 & 2 & 30.160 \\
\hline 08 & 9 & 400 & 2 & 3 & 10.004 \\
\hline 09 & 9 & 500 & 4 & 1 & 51.207 \\
\hline & & & & & \\
\hline
\end{tabular}

\section{RESULTS \& DISCUSSION}

\subsection{EDM PARAMETR EFFECT ON WR}

WR is one of the important factors of machining which helps to enhance the productivity, reduce the production time and make the product more economical. Signal to Noise ratio was determined by using the technique larger is better shown in table 5[15].

ANOVA table 6 implies that pulse current and percentage of reinforcement having the significant effect on WR. It is found that on increasing the $\mathrm{T}_{\mathrm{ON}}$ time WR initially decreases upto $400 \mu \mathrm{sec}$ and after that start to increase. 
On increasing the pulse on time pressure inside the plasma channel starts to decrease which decrease the MRR as a result of which WR decreases. But beyond $400 \mu$ sec because of longer effect of high thermal energy TWR becomes low as a result of which WR again starts to increase.

Table 5. Signal to Noise ratio for WR

\begin{tabular}{|c|c|c|c|c|}
\hline Level & SVO & $\mathbf{T}_{\mathbf{O N}}$ & $\mathbf{I}$ & $\mathbf{S}$ \\
\hline 1 & 30.75 & 32.30 & 28.27 & 32.66 \\
\hline 2 & 30.34 & 26.18 & 32.07 & 29.71 \\
\hline 3 & 27.93 & 30.54 & 28.68 & 26.65 \\
\hline
\end{tabular}

Pulse current also affects the WR as shown in table 6. It is shown in Fig. 3 that WR is first increases on increasing pulse current upto 4 ampere after that start to decrease. On increasing pulse current both electrodes subjected to high thermal energy which enhance the WR. After 4 ampere pulse current WR start to decrease because high thermal energy enhance the crater size which produces resistance in the conductive path after the removal of ceramic particles. Hence WR decreases beyond 4 ampere pulse current.

Table 6. Analysis of variance for WR

\begin{tabular}{|c|c|c|c|c|c|}
\hline Source & $\boldsymbol{d} \boldsymbol{f}$ & Seq.SS & Adj.SS & Adj.MS & \% Contribution \\
\hline $\mathrm{SVO}$ & 2 & 61.17 & 61.170 & 30.585 & 3.86 \\
\hline $\mathrm{T}_{\mathrm{ON}}$ & 2 & 603.66 & 603.663 & 301.832 & 38.10 \\
\hline $\mathrm{I}$ & 2 & 291.06 & 291.058 & 145.529 & 18.37 \\
\hline $\mathrm{S}$ & 2 & 628.51 & 628.513 & 314.257 & 39.67 \\
\hline Total & 8 & 1584.40 & & & 100 \\
\hline
\end{tabular}

It is found that on increasing the percentage of reinforcement WR decreases as shown in fig. 3. On decreasing the percentage of graphite MRR decreases because graphite having good thermal conductivity as a result of which WR also decreases. But on increasing the percentage of boron carbide MRR decreases and TWR increases as a result of which WR decreases. Fig. 3 shows that WR is decreases non-linearly with increase in survo voltage.

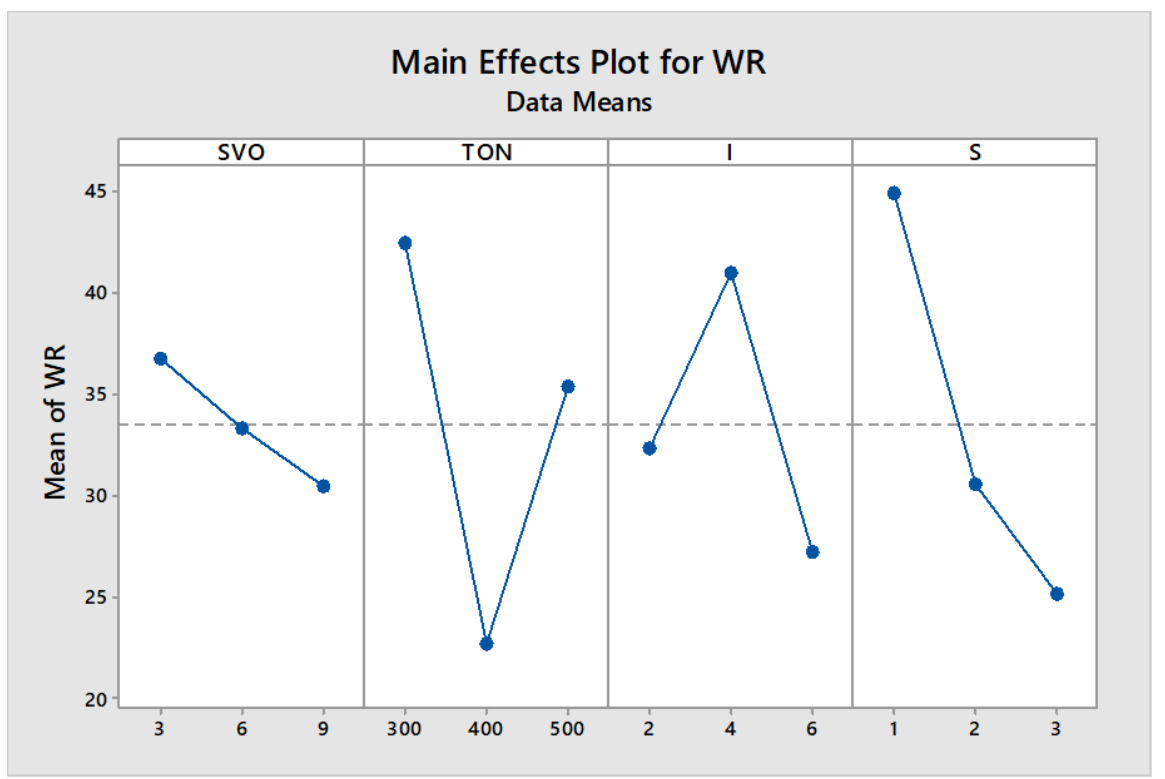

Fig. 3 Parametric Effect on WR during EDM 


\section{PREDICTION OF RESULTS}

Table 7. Comparison between predicted and finding results

\begin{tabular}{|c|c|c|c|}
\hline & \multicolumn{3}{|c|}{ Optimum machining parameter } \\
\hline & & Predicted result & Investigated result \\
\hline \multirow{2}{*}{ WR } & Level & A1B1C2D1 & A1B1C2D1 \\
\hline & WR & 64.688 & 924.227 \\
\hline & S/N ratio for WR & 38.7668 & 59.3156 \\
\hline
\end{tabular}

Table 7 implies that for WR, there is acceptable variation between predicted and experimental result.

\section{CONCLUSIONS}

This experimentation highlights the effect of process parameter on the machining responses in term of WR during the $\mathrm{EDM}$ of $\mathrm{Al} / \mathrm{B}_{4} \mathrm{C} / \mathrm{Gr}$ metal matrix composite [16].

On increasing the $\mathrm{T}_{\mathrm{ON}}$ time WR initially decreases upto $400 \mu \mathrm{sec}$ and after that start to increase. WR is first increases on increasing pulse current upto 4 ampere after that start to decrease. On increasing the percentage of reinforcement WR decreases. WR is decreases in non-linearly fashion with increase in survo voltage. Taguchi Analysis has been used to design the experimental work and their fitness and adequacy has been tested through the analysis of variance (ANOVA).

\section{ACKNOWLEDGEMENT}

We would conjointly prefer to show our feeling to the Dr. Subhash Singh (Assistant Professor, National Institute of Technology Jamshedpur, Jharkhand, India) for sharing their pearls of knowledge with us throughout the course of this analysis. The authors also like to express special thanks to Indo Danish Tool Room, Jamshedpur, Jharkhand for allowing us to conduct the experimental work.

\section{REFRENCES}

[1] Rizwee, M., Minz, S. S., Orooj, M., Hassnain, M. Z., Khan, M. J., 2019. Electric discharge machining method for various metal matrix composite materials. International Journal of Innovative Technology and Exploring Engineering, 8 (9), 1796-1807.

[2] Rizwee, M., Rao, P.S., Khan, M.Y., 2020. Recent advancement in electric discharge machining of metal matrix composite materials. Materials Today: Proceeding. (Available online)

[3] George, P. M., Raghunath, B. K., Manocha, L. M., \& Warrier, A. M. (2004). EDM machining of carbon-carbon composite - a Taguchi approach. Journal of Materials Processing Technology, 145(1), 66-71.

[4] Pandey, S., \& Shrivastava, P. K. (2020). Vibration-assisted electrical arc machining of $10 \%$ B4C/Al metal matrix composite. Proceedings of the Institution of Mechanical Engineers, Part C: Journal of Mechanical Engineering Science, 234(6), 1156-1170.

[5] Khan, M. Y., Rao, P. S., Pabla, B. S., 2020. Investigations on the feasibility of jatropha curcas oil based biodiesel for sustainable dielectric fluid in EDM process. Materials Today: Proceedings, 26, 335-340.

[6] Khan, M. Y., Rao, P. S., Pabla, B. S., 2020. Powder mixed electrical discharge machining (PM-EDM): A methodological review. Materials Today: Proceedings. (Available online)

[7] Khan, M.Y., Rao, P.S., Pabla, B.S., 2020. Review of electrical discharge machining process with nanopowder and CNT mixed dielectric fluid. In Proceedings of $4^{\text {th }}$ International Online Multidisciplinary Research Conference (IOMRC-2020), Hyderabad, October 23.

[8] Dhar, S., Purohit, R., Saini, N., Sharma, A., \& Kumar, G. H. (2007). Mathematical modeling of electric discharge machining of cast $\mathrm{Al}-4 \mathrm{Cu}-6 \mathrm{Si}$ alloy-10 wt.\% SiCP composites. Journal of materials processing technology, 194(1-3), 24-29.

[9] Senthilkumar, V., \&Omprakash, B. U. (2011). Effect of Titanium Carbide particle addition in the aluminium composite on EDM process parameters. Journal of Manufacturing Processes, 13(1), 60-66. 
[10] P.Sudhakar Rao, P.K. Jain, D.K. Dwivedi, “Optimization of Key Process Parameters on Electro Chemical Honing (ECH) of External Cylindrical Surfaces of Titanium Alloy Ti-6Al- 4V" Elsevier Publishers, J. of Materials Today Proceedings, Vol 4, Issue 2, Part A (2017), 2279-2289.

[11] P.Sudhakar Rao, P.K. Jain, D.K. Dwivedi, "Study and Prediction of Surface Finish of External Cylindrical Surfaces of Titanium Alloy by Electro Chemical Honing (ECH) Process" in $23^{\text {rd }}$ international conference on PFAM-2014 at IITR, Roorkee during 05-07 Dec, 2014.

[12] P.Sudhakar Rao, P.K. Jain, D.K. Dwivedi, "Study and Effect of Process Parameters on External Cylindrical Surfaces of Titanium Alloy by Electro Chemical Honing (ECH) Process” in 26th DAAAM International symposium on intelligent manufacturing and automation 2015 during 21-24 October, 2015 at Zadar, Croatia, EU.

[13] P.Sudhakar Rao, P.K. Jain, D.K. Dwivedi, "Optimization of Key Process Parameters on Electrochemical Honing (ECH) of External Cylindrical Surfaces of Titanium Alloy Ti-6Al-4V" in $5^{\text {th }}$ International Conference on Materials Processing and Characterization ICMPC - 2016 at GRIET, Hyderabad during 12-13 Mar, 2016.

[14] P.Sudhakar Rao, P.K. Jain, D.K. Dwivedi, "Prediction of Optimal Process Parameters on to Electro Chemical Honing (ECH) of External Cylindrical Surfaces of Titanium Alloy Using

DOE Technique" in $6^{\text {th }}$ International and $27^{\text {th }}$ All India Manufacturing Technology, Design $\quad$ and Research Conference (AIMTDR 2016) at COEP, Pune during 16-18 Dec, 2016.

[15] P.Sudhakar Rao, P.K. Jain, D.K. Dwivedi, "Effect of Electrolyte Composition on Surface Finish of Titanium Alloy by Electro Chemical Honing Process" in $1^{\text {st }}$ international conference on ICNDME2014 at MMU, Mullana (Ambala) during 21-22 Dec 2014.

[16] P.S. Rao, P.K. Jain, D.K. Dwivedi, "Electro Chemical Honing (ECH) of External Cylindrical Surfaces of Titanium Alloy”, Elsevier Publishers, J. of Procedia engineering, 100 (2015), 936-945. 